\section{Characterization of Anatomical and Physiological Effects of Variegation Mutation on Grapevine}

\author{
Jack Olson and Matthew Clark \\ Department of Horticultural Science, University of Minnesota-Twin Cities, \\ St. Paul, MN 55108
}

Additional index words. chlorophyll, chloroplast, grape, histology, plant cell, Vitis

\begin{abstract}
Variegation is a common trait in plants that characteristically displays white or off-colored plant tissue. In grapevine, leaf variegation is expressed as white and pale green leaf tissue resulting in plants that are stunted in growth and hindered in development. In this study, several experiments were performed to investigate the impact of this mutation has on the anatomy of grape leaves and physiology of the plant. Histological staining of variegated and nonvariegated leaf tissue transections showed alterations to the leaf palisade mesophyll structure that affected leaf tissue width. An assay quantifying leaf pigments was performed to compare chlorophyll and carotenoid concentrations in leaves between variegated and wild-type seedlings, which showed that variegated leaf samples had reduced chlorophyll and carotenoid concentration. Through fluorescence imaging, we determined that photochemical efficiency of photosystem II (PSII) is reduced in variegated seedlings. By growing variegated and wild-type plants under high, medium, and low light intensities that variegated plants exposed to higher light intensity reduces the phenotypic expression of the variegation trait. Also, we found variegated plants to have significant reductions in growth traits such as plant height, leaf number, branch number, and dry weight compared with wild-type phenotype plants. Overall, our experiments revealed the variegation mutation altered normal leaf development causing significant effects to grapevine physiology.
\end{abstract}

Variegation is a phenotype where plants develop off-colored sectors in their vegetative or reproductive tissues that can be caused by several types of genetic changes (Yu et al., 2007). In general, variegated plant tissues typically display white, pale green, or yellow tissues that are different from the plant species' normal, or wild-type (WT), phenotype. Grapevine (Vitis spp.) plants possessing this trait have highly variable expression and have sectors of homogeneous tissue with no clear pattern formation. Thus, variegation on grapevine leaves can be described as nonpatterned and sectorial (Kirk and Tilney-Bassett, 1978). In the University of Minnesota grape breeding program, variegation is commonly segregating among progeny of breeding populations and is largely unwanted for several apparent adverse effects on the seedlings. One reason is that variegated grapevine plants are hindered in growth in relation to a nonvariegated, WT plant. Variegated grapevine seedlings that survive and are subsequently planted in the nursery are typically culled after the season due to poor overall performance. On the basis of these observations in the breeding program, we have

Received for publication 15 Apr. 2021. Accepted for publication 16 July 2021.

Published online 3 September 2021.

M.C. is the corresponding author. E-mail: clark776@umn.edu.

This is an open access article distributed under the CC BY-NC-ND license (https://creativecommons. org/licenses/by-nc-nd/4.0/). determined the trait as being sublethal, meaning variegation does not result in complete lethality and the plant is able to survive, but it has negative consequences on plant fitness and reduces the plant's chance of surviving in field conditions. Limited research has examined the effects or consequences of variegation in Vitis (Filler et al., 1994; Rathjen and Robinson, 1992), but several other variegated plant species have been investigated such as Arabidopsis thaliana (Aluru et al., 2001; Rosso et al., 2009; Wetzel et al., 1994), Silybum marianum (Shelef et al., 2019), Arum italicum (La Rocca et al., 2011), and Begonia spp. (Sheue et al., 2012).

Several studies have attempted to determine the type of variegation by examining differences in leaf tissue anatomy between variegated and WT plants. Sheue et al. (2012) looked at six species of variegated Begonia using light and electron microscopy and reported the "air space" type of variegation based on differences in chlorenchyma cell shapes and chloroplast locations. Aluru et al. (2001) found green sectors to have thicker than normal leaf tissue due to an increase in epidermal and mesophyll cell size and an increase in air space volume in the variegated leaves in the Arabidopsis thaliana mutant immutans. White sectors had normal thickness, but palisade cells failed to expand normally. Similarly, Wetzel et al. (1994) examined electron micrographs of chloroplasts from white sector cells of immutans and reported an abnormal, vacuolated plastid structure which lacked organized thylakoid membranes. In a study on variegated Pulmonaria officinalis L., the light green sectors were caused by the presence of loosely arranged cells in the palisade parenchyma (Esteban et al., 2008). The studies presented here show variegation-induced changes to leaf anatomy and plastid structure resulting in different colored leaf tissue.

Because variegated leaves express different colors than the normal phenotype, researchers have examined whether there are changes in content of chlorophyll (Chl) $a / b$ and carotenoid pigments. This type of variegation is called pigment-related variegation, originally described by Hara (1957) in his findings of four general mechanism for variegation from his studies on 55 variegated plant species. Chl $a / b$ are essential pigments in plants for harvesting light used in photosynthesis to produce energy, and carotenoids are essential for photoprotection of chloroplast photosystems via nonphotochemical quenching (Bartley and Scolnik, 1995). Phytoene, a carotenoid biosynthesis intermediate, has been found to accumulate in the white areas of variegated leaf tissue in immutans and the tomato ghost mutant, suggesting that there is an interaction between carotenoid biosynthesis and variegation (Barr et al., 2004; Wetzel et al., 1994). Variegated Coleus $\times$ hybridus had significant differences in $\mathrm{Chl}$ and carotenoid content between green sectors and creamy-yellow areas (Borek et al., 2016). In two of the cultivars, the creamy-yellow sector's $C h l a / b$ ratio was $\approx 5$ times lower compared with green sectors. In variegated Arum italicum, pale-green variegated sectors had 26\% less Chl than normal, dark-green sectors (La Rocca et al., 2011). In the Arum thaliana mutant immutans, variegated seedlings had a 4- to 5-fold decrease in Chl accumulation under exposure of continuous high light treatment (Rosso et al., 2009).

Photosynthesis is another common parameter typically measured in studies comparing variegated to WT plants. Most studies found that variegated plants photosynthesized at a similar rate to WT plants which suggests that the variegated plants are able to compensate for a lack of pigments in some tissue of the leaf (Esteban et al., 2008; La Rocca et al., 2011; Shelef et al., 2019; Sheue et al., 2012).

Numerous genes are light regulated, and chloroplast development is light dependent (Ernst and Schefbeck, 1988). Phenotypic expression of variegation in Vitis is highly variable and investigation of the environmental factors that influence its expression, like light or temperature, is limited. Galzy and Galzy (1964) investigated the effect of temperature on variegation expression in a mutant of the $V$. vinifera variety 'Aramon'. They reported variegation was only expressed when grown at $20^{\circ} \mathrm{C}$, but not at $35^{\circ} \mathrm{C}$, indicating that temperature may influence the expression. In immutans, phenotypic expression of variegation is increased by exposure to high temperatures and light intensities, which led researchers to believe that light was a factor in the mechanism of variegation (Rédei, 1963; Röbbelen, 1968; Rosso et al., 2009). Identifying whether light influences 
expression of variegation in grapevine may provide some insight that its mechanism is regulated by light.

Limited research has characterized the anatomical and physiological effects of variegation on Vitis plants. Therefore, this study attempts to characterize the effects of variegation by pursuing five objectives: 1) examine changes to leaf anatomy and cellular structure, 2) compare Chl and carotenoid concentration in leaves between variegated and WT seedlings, 3) investigate whether photochemical efficiency of PSII is altered in variegated seedlings, 4) examine whether light intensity affects the expression of variegation, and 5) compare growth performance between variegated and WT plants under different light intensities.

\section{Materials and Methods}

Histology of variegated and WT leaf tissue sectors. Small pieces of leaf tissue, $\approx 1 \mathrm{~cm}^{2}$ or less, were excised from mature leaves of WT and variegated plants in a segregating $F_{1}$ population derived from a cross of MN1256 $\times$ MN1327. Plants were grown in a greenhouse in the Plant Growth Facilities at the University of Minnesota in St. Paul, MN, at an average temperature of $22^{\circ} \mathrm{C}$ and a daylength of $16 \mathrm{~h}$. Three types of leaf tissue were sampled for examination: white variegated sector, light green variegated sector, and WT sector. Each leaf tissue sample was placed into glass vials containing $4 \%$ paraformaldehyde in phosphate-buffered saline solution and set in a vacuum for $30 \mathrm{~min}$. The paraformaldehyde solution was replaced several times and samples stored at $4{ }^{\circ} \mathrm{C}$ for $2 \mathrm{~d}$. The samples were then put through an ethanol and sodium chloride solution series $(30 \%, 50 \%, 70 \%$ ethanol with $130 \mathrm{~mm} \mathrm{NaCl} ; 1.5 \mathrm{~h}$ each) for dehydration. Samples were subjected to another ethanol solution series $(80 \%, 95 \%, 100 \% ; 1.5 \mathrm{~h}$ each) without sodium chloride for additional dehydration removal of remaining sodium chloride. Afterward, samples were put through a series of Histo-Clear II-ethanol solutions at room temperature $(25 / 75,50 / 50,75 / 25$, and $100 \%$ Histo-Clear II; $1.5 \mathrm{~h}$ each), to remove ethanol from the tissue sections. Next, paraffin wax chips were added to the vials until saturated. Saturated vials were moved to a heat chamber set at $58^{\circ} \mathrm{C}$ and the wax solution was replaced several times.

Next, samples were sectioned transversely into $10-\mu \mathrm{m}$ thin sections using a microtome (Model 820; American Optical, Buffalo, NY). The paraffin wax-ribbon sections were mounted on microslides and dewaxed in $100 \%$ HistoClear II solution. Slides were rinsed in $100 \%$ ethanol and left to air dry. Slides were placed into a staining jar with $1 \%$ methylene blue solution for $5 \mathrm{~min}$, then into Lugol's iodine solution for starch staining for $5 \mathrm{~min}$. After staining, slides were rinsed with distilled water and placed on a slide warmer to dry. Sections were mounted and sealed using a coverslip and Permount. Stained sections were observed and imaged using a light microscope under a total magnification of $\times 200$ (Ernst Leitz Wetzlar
307-143.004 microscope; Ernst Leitz GmbH, Wetzlar, Germany). Photomicrographs of white, light green, and WT tissues were captured using SPOT Insight 4 camera and accompanying SPOTBasic software (SPOT Imaging Solution, Sterling Heights, MI) and transverse leaf width was measured using Fiji software (Schindelin et al., 2012). Ten measurements were taken across each leaf tissue section sample $(n=5$ per tissue type) and averaged to determine the tissue width for that sample. Comparisons between tissue types were made in $\mathrm{R}$ software ( $\mathrm{R}$ Core Team, 2019) by performing a one-way analysis of variance (ANOVA). A post hoc test was subsequently performed to evaluate significant differences among tissue types using 'TukeyHSD' function of 'multcompView' package in R (Graves et al., 2015; R Core Team, 2019).

Light experiment. Three treatments varying in light intensity were used to test for differences in various plant growth-related traits between variegated and WT grape seedlings, as well as to determine whether light intensity influences phenotypic expression of variegation. Seeds were collected from an $\mathrm{S}_{1}$ population of the grape variety 'Landot Noir', sown into trays containing Purple Cow Organics Seed Starter Mix, and placed into a greenhouse for germination. Seedlings were phenotyped for variegation and grouped accordingly at the cotyledon stage of development.

At the first true leaf stage, seedlings were transplanted into individual pots containing Sungro Professional Growing Mix and placed into EGC GCW-15 growth chambers, with T5841 fluorescent and incandescent/halogen lighting. The three light treatments were high $\left(360 \mu \mathrm{mol}\right.$ photons $\left./ \mathrm{m}^{2} / \mathrm{s}\right)$, moderate $(210 \mu \mathrm{mol}$ photons $\left./ \mathrm{m}^{2} / \mathrm{s}\right)$, and low $\left(60 \mu \mathrm{mol}\right.$ photons $/ \mathrm{m}^{2} /$ s). Ninety plants of each phenotype were evaluated. Thirty plants from each phenotypic group were randomly assigned to a treatment and spaced in an alternating pattern to reduce shading from any adjacent plant. The light intensity within each growth chamber was calibrated and checked daily using an Apogee Instruments MQ-500 PAR reader (Logan, UT). All growth chambers were set at $16 / 8$-h light cycles at a temperature of $25 / 20^{\circ} \mathrm{C}$, respectively, with $70 \%$ relative humidity. Plants were watered every other day.

Traits measured 6 weeks after the light treatments started were plant height, leaf number, branch number (count of axillary shoots), and whole plant dry weight. The first three true leaves from the base of each plant were collected and immediately imaged on an Epson Perfection V550 Photo Scanner (Long Beach, CA). Dry weight measurements were performed after $6 \mathrm{~d}$ of sample drying in an oven at $63{ }^{\circ} \mathrm{C}$. Differences between groups and treatments for each of the traits measured were examined by performing a two-way ANOVA at a $95 \%$ confidence interval in $\mathrm{R}$ software (R Core Team, 2019).

Unexpectedly, a third variegated phenotype was observed among WT and variegated seedlings in the first true leaf (Fig. 1D). This new variegated phenotype, which displayed a

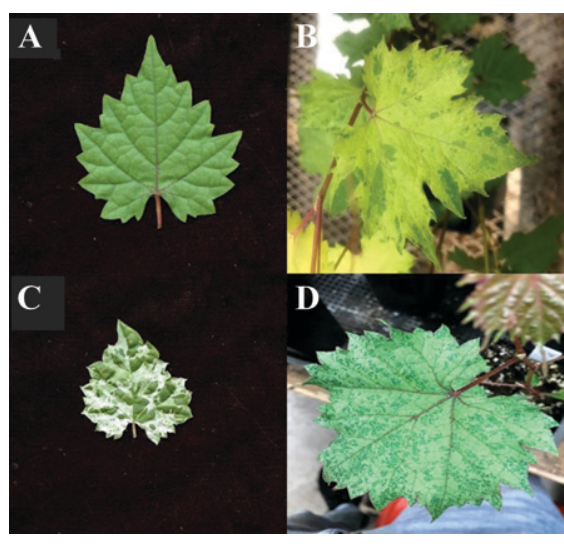

Fig. 1. Photographs of leaf samples of wild-type (A) and variegated [light green (B), white (C), spotty (D)] phenotypes.

spot-like appearance, has never been observed among our other variegated populations. These unique samples, along with plants that shortly died after being placed into treatment, were removed from statistical analysis for a balanced dataset that included WT and the classic variegated trait we commonly observed.

For leaf image analysis, three leaves from each variegated plant $(n=42)$ were segmented by sector using RGB color space in Food Color Inspector software version 4.0 (http://www.cofilab.com/portfolio/food-colorinspector/; Fig. 2). Segmented images were imported into R software for determination of pixel proportion using the "countcolors" package for each color segmentation (R Core Team, 2019; Weller, 2019). The percent variegated area for each plant was averaged across its three leaves. A one-way ANOVA at a $95 \%$ confidence interval was conducted to determine differences in average percent variegated area among treatments, and a Tukey's honest significant difference (HSD) test was performed (Graves et al., 2015; R Core Team, 2019).

Chlorophyll and carotenoid assay. Sixty seeds from an 'Itasca' $\mathrm{S}_{2}$ population were germinated in trays and grown in the greenhouse for pigment assays. Thirty WT and 30 variegated seedlings were sampled. Each

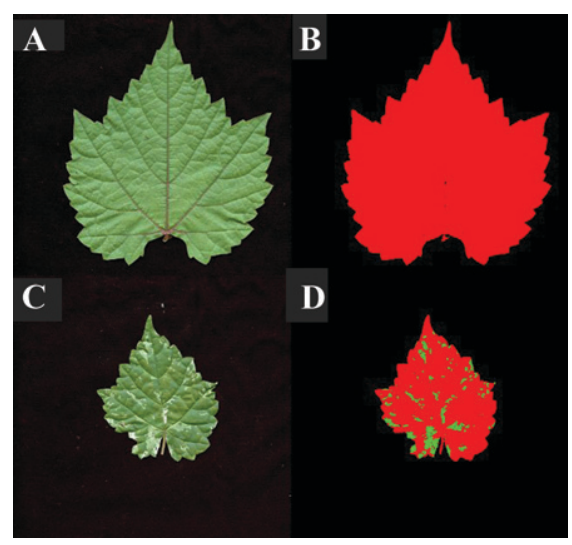

Fig. 2. Examples of segmentation analysis of wild-type (A, B) and variegated $(\mathbf{C}, \mathbf{D})$ seedling grape leaf samples. 
assay was performed on a single $1-\mathrm{cm}^{2}$ leaf sample excised from the middle of a mature leaf. Three assays in total were conducted in 2-week intervals on 22 Apr. 2020, 5 May 2020, and 22 May 2020. All assays were performed on the same plants representing the different phenotypes. Each leaf sample was placed in a vial containing $5 \mathrm{~mL}$ of dimethylformamide and incubated in the solvent for $24 \mathrm{~h}$ under dark conditions at $5.6^{\circ} \mathrm{C}$. After incubation, the extracted pigments in the solvent were placed into a cuvette for measurement in a ThermoFisher Scientific Nanodrop 2000 spectrophotometer (Waltham, MA) for absorbance measurements at a resolution of 1 to $4 \mathrm{~nm}$. The equations shown below from Wellburn (1994) were used for calculating carotenoid concentration. Chl $a$, Chl $b$, total Chl $(\mathrm{Chl} a+b)$ and protochlorophyllide concentration were calculated using equations from Moran (1982). Student's $t$ test was performed for each assay to determine whether there were significant differences variegated and WT samples. (1994):

Total carotenoid equation from Wellburn

$\mathrm{C}_{\mathrm{x}+\mathrm{c}}=\left(1000 \mathrm{~A}_{480}-0.89 \mathrm{C}_{\mathrm{a}}-52.02 \mathrm{C}_{\mathrm{b}}\right) / 245$

Chlorophyll equations from Moran (1982):

Chlorophyll $a=12.81_{\mathrm{A}_{664}}-2.16 \mathrm{~A}_{647}$

$$
+1.44 \mathrm{~A}_{625}-4.91 \mathrm{~A}_{603}
$$

Chlorophyll $b=-4.93 \mathrm{~A}_{664}+26.01 \mathrm{~A}_{647}$

$$
+3.74 \mathrm{~A}_{625}-15.55 \mathrm{~A}_{603}
$$

Protochlorophyllide $=-2.52 \mathrm{~A}_{664}-0.79 \mathrm{~A}_{647}$

$$
+36.55 \mathrm{~A}_{625}-27.08 \mathrm{~A}_{603}
$$

Total Chlorophyll $=8.24 \mathrm{~A}_{664}+23.97 \mathrm{~A}_{647}$

$$
-16.64 \mathrm{~A}_{603}
$$

Chlorophyll fluorescence experiment. Seeds from an MN1220 $\mathrm{S}_{1}$ population $(\mathrm{n}=$ $108)$ and an 'Itasca' $S_{2}$ population $(n=93)$ were sown and germinated in trays in the greenhouse. The MN1220 $\mathrm{S}_{1}$ population was composed of 23 variegated seedlings, and the rest of the seedlings (70) with normal WT phenotype. The Itasca $\mathrm{S}_{2}$ population had 33 variegated seedlings and 75 seedlings with WT phenotype. To have a balanced design with an equal number of variegated and WT groups in each population, 47 WT samples were randomly removed from the MN1220 $\mathrm{S}_{1}$ population, and $42 \mathrm{WT}$ samples were randomly removed from the 'Itasca' $S_{2}$ population for analysis.
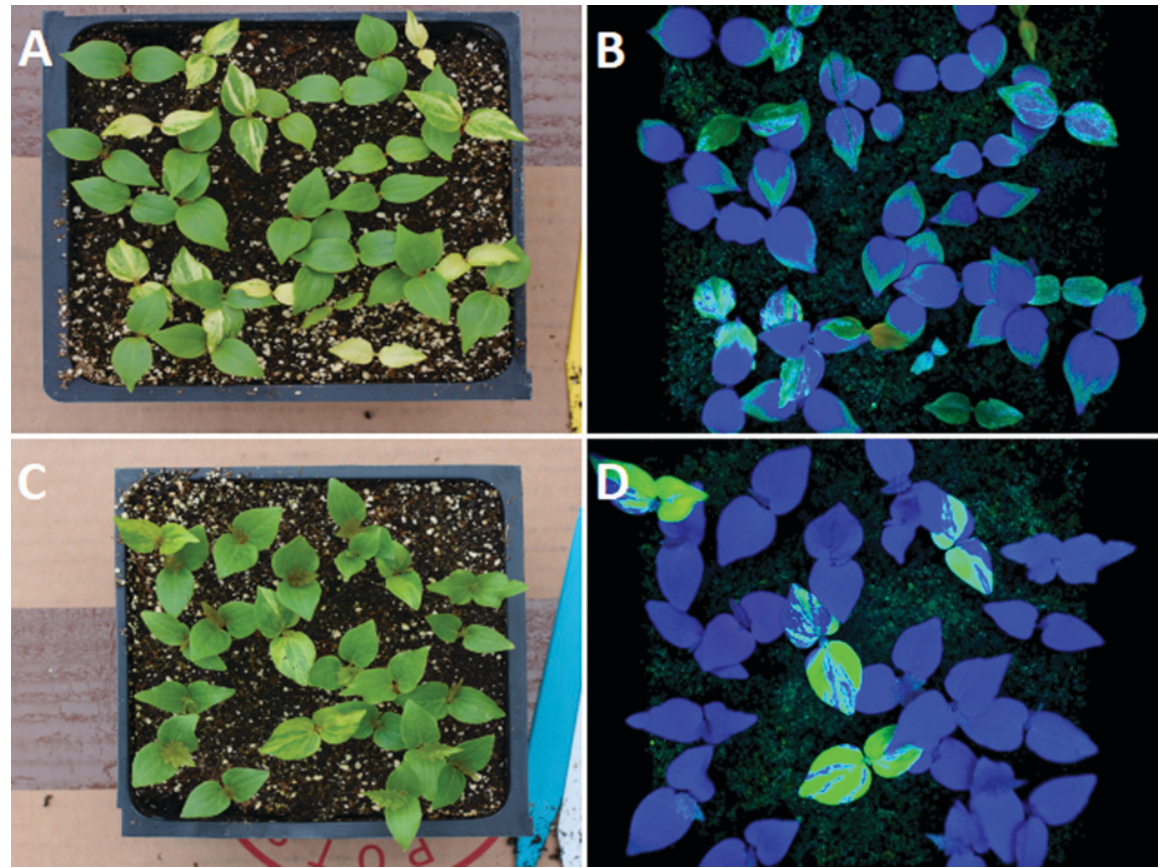

Fig. 3. Digital RGB photographs $(\mathbf{A}, \mathbf{C})$ and chlorophyll fluorescence images $(\mathbf{B}, \mathbf{D})$ of seedling trays used in chlorophyll fluorescence imaging. Seedlings from an 'Itasca' $S_{2}$ population $(\mathbf{A}, \mathbf{B})$ and from an MN1220 $\mathrm{S}_{1}$ population $(\mathbf{C}, \mathbf{D})$. Blue coloration indicates normal PSII quantum yield, which indicates a $\mathrm{Y}$ (II) value near 0.8 . Green coloration indicates PSII quantum yield below a Y(II) value of 0.8 .

At the cotyledon stage, seedlings were placed in a cabinet and dark-adapted for 15 min before imaging. Using a Walz MAXI IMAGING-PAM M-Series machine (Effeltrich, Germany), the effective PSII quantum yield (Y(II)) as $\left(F_{m}^{\prime}-F\right) / F_{m}^{\prime}$ was measured for each tray of seedlings were captured using a light intensity of 3 and the aperture set at 1.7 (Fig. 3).

Images were analyzed using the region of interest (ROI) feature in ImagingWin software v2.56p from Walz. For measurements of each individual seedling, a single ROI was placed on 1 of the 2 cotyledons. WT and variegated groups were averaged across individuals for effective PSII quantum yield, and Student's $t$ test was conducted to determine differences between groups.

\section{Results}

Histological observations and tissue width analysis. Light green variegated leaf sectors were visibly reduced in palisade mesophyll cell length and density in comparison with WT palisade mesophyll cells (Fig. 4). The white variegated leaf lacked the mesophyll differentiation into distinct palisade and spongy parenchyma cells as opposed to the WT. Instead of palisade parenchyma, the adaxial surface composed of variously shaped parenchymatous cells. Nonetheless, it appeared to have a well-developed vascular system. Light green sectors showed a small reduction in starch staining, whereas white sectors showed nearly a complete absence of starch staining except in the vascular bundles. Reduced starch staining was especially apparent in the palisade mesophyll cells of white sectors in comparison with light green and normal WT sectors, although some starch staining was observable in the vascular bundles of white sectors.

Tissue width was visibly smaller in light green and white leaf sections in comparison with WT sections. These observations were supported by a significant difference in mean tissue width between groups $(P<0.05)$. WT sections had the highest average tissue width of $124.0 \mu \mathrm{m}$. Light green sections had an average tissue width of $105.4 \mu \mathrm{m}$ and white sections had the lowest average tissue width of $65.09 \mu \mathrm{m}$. The Tukey's HSD test revealed significant differences among all leaf section types.

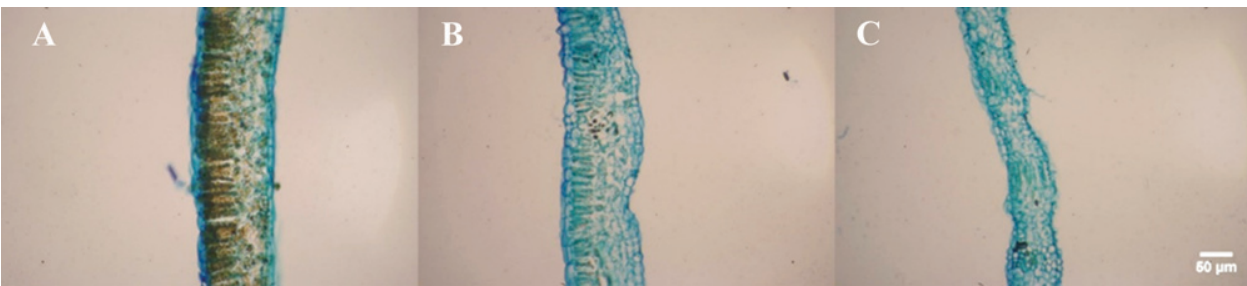

Fig. 4. Leaf tissue transect cross sections of wild-type (A), light green (B), and white (C) variegated cross sections. Leaf tissue cross sections were stained with methylene blue and Lugol's iodine. Cross sections observed and imaged under a total magnification of $\times 200$. Included is a scale bar of $50 \mu \mathrm{m}$ for reference. 
Table 1. The effects of phenotype (wild type or variegated; $\mathrm{df}=1$ ) and light treatment (low: $60 \mu \mathrm{mol}$ photons $/ \mathrm{m}^{2} / \mathrm{s}$; moderate: $210 \mu \mathrm{mol}$ photons $/ \mathrm{m}^{2} / \mathrm{s}$; high: $360 \mu \mathrm{mol}$ photons $/ \mathrm{m}^{2} / \mathrm{s} ; \mathrm{df}=2$ ) and phenotype $\times$ treatment interaction $(\mathrm{df}=2)$ on traits measured on grape seedlings population after 6 weeks of growth in the light experiment.

\begin{tabular}{lccc}
\hline & Phenotype & Treatment & Phenotype:Treatment \\
\hline Plant height & $* *$ & $*$ & NS \\
Leaf number & $*$ & $* *$ & NS \\
Branch number & $*$ & $* * *$ & NS \\
Dry weight & $* *$ & $* * *$ & NS \\
\hline NS, ${ }^{*}, * * * *$ Nonsignificant $(\alpha=0.05)$ or significant at $P<0.01,0.001$, or 0.0001, respectively.
\end{tabular}

Light experiment. Significant differences were found for all traits in both phenotype and light treatment effects (Table 1) but not the interaction effect. Variegated plants in high light treatment were $38 \%$ shorter than WT plants, had $32 \%$ fewer leaves, $50 \%$ fewer branches, and 39\% lower dry weight. Under moderate light treatment, variegated plants were $68 \%$ shorter, had $36 \%$ fewer leaves, $53 \%$ fewer branches, and $47 \%$ lower dry weight. Variegated plants under low light treatment were $60 \%$ shorter and had $32 \%$ fewer leaves, 94\% fewer branches, and 56\% lower dry weight. Means and standard errors are reported in Table 2.

On the basis of leaf image segmentation, variegated plants grown under low light showed the highest average percent variegated area of $11.3 \%$, whereas plants grown under moderate light expressed an average percent variegated area of $6.23 \%$. Plants grown under high light expressed the lowest average percent variegated area of $4.12 \%$.

Chlorophyll and carotenoid assay. The first two of three biweekly assays showed significant differences in one or more of the measured leaf pigments (Table 3 ). The first assay (22 Apr. 2020) performed on the first mature leaf found significant differences in Chl $a\left(298.61 \mathrm{mg} \cdot \mathrm{m}^{-2} \pm 11.63\right.$ and 242.89 $\mathrm{mg} \cdot \mathrm{m}^{-2} \pm 8.65$, WT and variegated respectively), total $\mathrm{Chl}\left(376.90 \mathrm{mg} \cdot \mathrm{m}^{-2} \pm 10.81\right.$ and $\left.314.16 \mathrm{mg} \cdot \mathrm{m}^{-2} \pm 14.28\right)$, and carotenoids $\left(61.50 \mathrm{mg} \cdot \mathrm{m}^{-2} \pm 1.79\right.$ and 54.59 $\mathrm{mg} \cdot \mathrm{m}^{-2} \pm 2.15$ ). The second assay (5 May 2020) on the second mature leaf only found a significant difference in carotenoids (57.79 $\mathrm{mg} \cdot \mathrm{m}^{-2} \pm 2.16$ and $\left.68.08 \mathrm{mg} \cdot \mathrm{m}^{-2} \pm 3.01\right)$. The third assay (22 May 2020) on the third leaf found no significant differences between WT and variegated groups (Fig. 5).

Photochemical efficiency of PSII. WT and variegated groups in the 'Itasca' $S_{2}$ population differed in photochemical efficiency of PSII (Y(II)) $(0.73 \pm 0.0041$ and $0.58 \pm 0.015$, respectively). Similarly, WT and variegated groups in the MN1220 $\mathrm{S}_{1}$ population significantly differed in $Y($ II) $(0.75 \pm 0.0021$ and $0.45 \pm$ 0.017 , respectively; Fig. 6).

\section{Discussion}

Variegated leaf tissue anatomy shows large differences in tissue width and mesophyll cell structure. Observations of variegated leaf tissue sectors under a light microscope revealed major anatomical differences in comparison with WT sectors. Organization of the palisade and spongy mesophyll layers was still intact in the light green variegated leaf tissue, but the white variegated leaf tissue had lost all organized structure. White variegated leaf tissue lacked distinct layers of adaxial palisade and abaxial spongy parenchyma cells similar to that observed in the bract, a modified leaf, as found in a cotton boll (Bondada et al., 1994). The effect of these changes to the palisade mesophyll cells in variegated sectors is evident by the analysis of tissue width, which showed a significant difference between variegated and WT sectors. Compared with WT, light green tissues showed a smaller reduction of $15 \%$, whereas white sectors tissue width was highly reduced by $47.5 \%$ in comparison with WT. In the case of light green sectors, the small reduction in tissue width is likely associated with the reduction in palisade mesophyll cell size. However, white sectors were nearly half the width of WT sectors suggesting that the loss of normal structure in palisade mesophyll cells has a large and direct effect on tissue width (Bondada et al., 1994). It is likely that a lack of mesophyll differentiation is due to the plant having insufficient energy for the differentiation process to occur.

These changes in tissue structure may have larger whole-plant implications, such as on leaf shape. Filler et al. (1994) previously described severely variegated leaves as having characteristic leaf shape deformity. We have similarly seen leaf shape deformities associated with severely variegated leaves in the form of curling or cupping along leaf margins and between veins (i.e., enations) suggesting that variegation affects normal leaf expansion. A similar phenomenon was observed in grapevine leaves injured by 2 , 4-D herbicide (Bondada, 2011a, 2011b).

Another observed difference was WT tissues had a normal presence of starch in its tissue indicated by dense black/brown staining of Lugol's iodine, whereas light green sectors were reduced in starch staining, and white sectors were nearly absent of stained starch. In light green tissue a reduced starch content may be a result of the smaller and less dense mesophyll cells containing a reduced amount of $\mathrm{Chl}$ for photosynthesis and subsequent starch production. In white tissue, a complete absence of starch in mesophyll cells likely suggests that the cells completely lack Chl and are thus unable to photosynthesize and produce starch. There is a small presence of starch in the white sector leaf vascular bundles, which may indicate that starch transport to the white sectors may be the key reason for these tissues staying alive. These findings are not unique in grapevine as a reduction in starch in variegated leaf tissues has also been observed in Pelargonium and Phalaenopsis aphrodite subsp. formosana (Chapman and Camp, 1932; Tsai et al., 2017).

The histological observations suggest that variegation in grapevine likely affects some aspect of chloroplast biogenesis. Mesophyll cells in white sectors are completely devoid of chloroplasts, whereas light green sectors have a reduced cellular size possibly due to a reduction of chloroplasts. A future electron microcopy examination of the plastids in light green and white sectors may provide more insight into the affected plastid components.

Light experiment reveals variegated plant growth is significantly hindered compared with WT. In greenhouse and field environments, we observed that variegated seedlings are often shorter and less vigorous than their WT siblings. We have also noted grapevine variegation is highly variable in its phenotypic expression. As a variegated grapevine matures, each new leaf will express more or less variegation than the previous one, but generally, variegated grapevine plants have reduced expression as they develop (J. Olson, personal observation). This may be a product of the growing cycle in the breeding program as seedling growth aligns with increasing daylength and temperature in the greenhouse, which may confound our observations. However, we observed that some variegated plants will exhibit a high expression in all leaves throughout their development. It has been previously reported that the immutans phenotype is directly affected by light intensity and

Table 2. Means $( \pm \mathrm{SE})$ of plant growth traits for variegated and wild-type grape seedlings grown under three different light intensities (low: $60 \mu \mathrm{mol}$ photons $/ \mathrm{m}^{2} / \mathrm{s}$; moderate: $210 \mu \mathrm{mol}$ photons $/ \mathrm{m}^{2} / \mathrm{s}$; high: $360 \mu \mathrm{mol}$ photons $/ \mathrm{m}^{2} / \mathrm{s}$ ).

\begin{tabular}{|c|c|c|c|c|c|c|}
\hline \multirow[b]{2}{*}{ Trait } & \multicolumn{3}{|c|}{ Wild type $(n=14)$} & \multicolumn{3}{|c|}{ Variegated $(n=14)$} \\
\hline & Low & Moderate & High & Low & Moderate & High \\
\hline Plant height $(\mathrm{cm})$ & $33.3( \pm 4.94)$ & $39.8( \pm 6.58)$ & $53.7( \pm 5.80)$ & $19.9( \pm 2.45)$ & $26.9( \pm 4.62)$ & $33.3( \pm 5.55)$ \\
\hline Leaf number & $12.9( \pm 1.36)$ & $18.2( \pm 3.53)$ & $28.5( \pm 5.96)$ & $8.79( \pm 0.366)$ & $11.7( \pm 1.10)$ & $18.4( \pm 2.94)$ \\
\hline Dry weight (g) & $1.00( \pm 0.155)$ & $2.25( \pm 0.410)$ & $3.97( \pm 0.665)$ & $0.44( \pm 0.0781)$ & $1.20( \pm 0.284)$ & $1.91( \pm 0.336)$ \\
\hline
\end{tabular}


Table 3. Comparison of variegated and wild-type grape seedlings grown in a growth chamber for leaf pigment concentrations using a two-sample $t$ test $(\mathrm{n}=30)$. Three assays were repeated every 2 weeks. $P$ values are given for each assay on 22 Apr. 2020, 5 May 2020, and 22 May 2020.

\begin{tabular}{lccc}
\hline \multicolumn{1}{c}{ Trait } & 22 Apr. 2020 & 5 May 2020 & 22 May 2020 \\
\hline Chlorophyll $a$ & $* * *$ & NS & NS \\
Chlorophyll $b$ & NS & NS & NS \\
Total Chlorophyll $(a+b)$ & NS & NS & NS \\
Protochlorophyllide & NS & $* *$ & NS \\
Carotenoid & $*$ & NS \\
\hline
\end{tabular}

NS, *,**,***Nonsignificant $(\alpha=0.05)$ or significant at $P<0.05,0.01$, or 0.001 , respectively.

its expression is increased with higher light intensities (Rédei, 1963; Röbbelen, 1968; Rosso et al., 2009). Galzy and Galzy (1964) reported increased variegation in plants grown at $20^{\circ} \mathrm{C}$ but not at $35^{\circ} \mathrm{C}$, suggesting that temperature may be a regulatory factor in its mechanism. In this experiment, we were interested in testing whether light influences the phenotypic expression in variegated grape plants.

Variegated plants underperformed in all vigor-related traits compared with WT. Significant effects were found for both light treatment and phenotype (Table 1). When averaging the traits across all treatments, variegated plants had $63 \%$ shorter plant height; $65 \%$ reduction in number of leaves; $44 \%$ reduction in branch number, and 55\% reduction in dry weight. These large reductions in growth-related traits indicates that variegation severely affects plant vigor and contributes to basis of histological observations, we believe these large reductions in plant-growth-related traits that contribute to sublethality are due to a reduced amount and/or lack of Chl. The Chl assay we performed supports this idea, as we found reduced concentrations of $\mathrm{Chl}$ in variegated plants compared with WT plants. A lack of sufficient Chl and other photopigments may result in an over accumulation of electrons that are unable to be efficiently quenched leading to damage to the chloroAlso, the lack of $\mathrm{Chl}$ in variegated seedlings reduces the production of photosynthetic products (i.e., sugar and, eventually, starch) likely affecting the rate at which metabolic growth processes can occur. A future study measuring total carbohydrates or carbohydrate partitioning could test this hypothesis. weak plant growth and development. On the plast photosystems from photo-oxidation.
The image analysis of variegated plants comparing the proportion of variegated area at different light intensities did not fit our hypothesis that higher light intensities would increase expression of variegation as reported in immutans (Rosso et al., 2009). In this experiment, the opposite occurred. Variegated plants under low light showed a 7\% increase in variegated area compared with those under high light. Variegated plants under moderate light intensity also had a lower percent variegated area compared with plants under low light intensity by $\approx 5 \%$. Although we found large, significant differences between treatments, the results in this experiment should only be considered preliminary due to the lack of replication. It is possible that the mechanism of variegation is influenced by light, and lower light increases its expression, but confidence in these findings for both growth-related traits and phenotypic expression would require future studies with a larger sample size and replication.

Chl and carotenoid assay shows reduced differences in Chl and carotenoid concentration. Because variegation expresses as white and off-color leaf tissue, we hypothesized that the concentration of $\mathrm{Chl}$ would be reduced in variegated leaf tissue. Several studies of variegated plants in a variety of species have reported a reduction in $\mathrm{Chl}$ compared with their WT counterparts (Borek
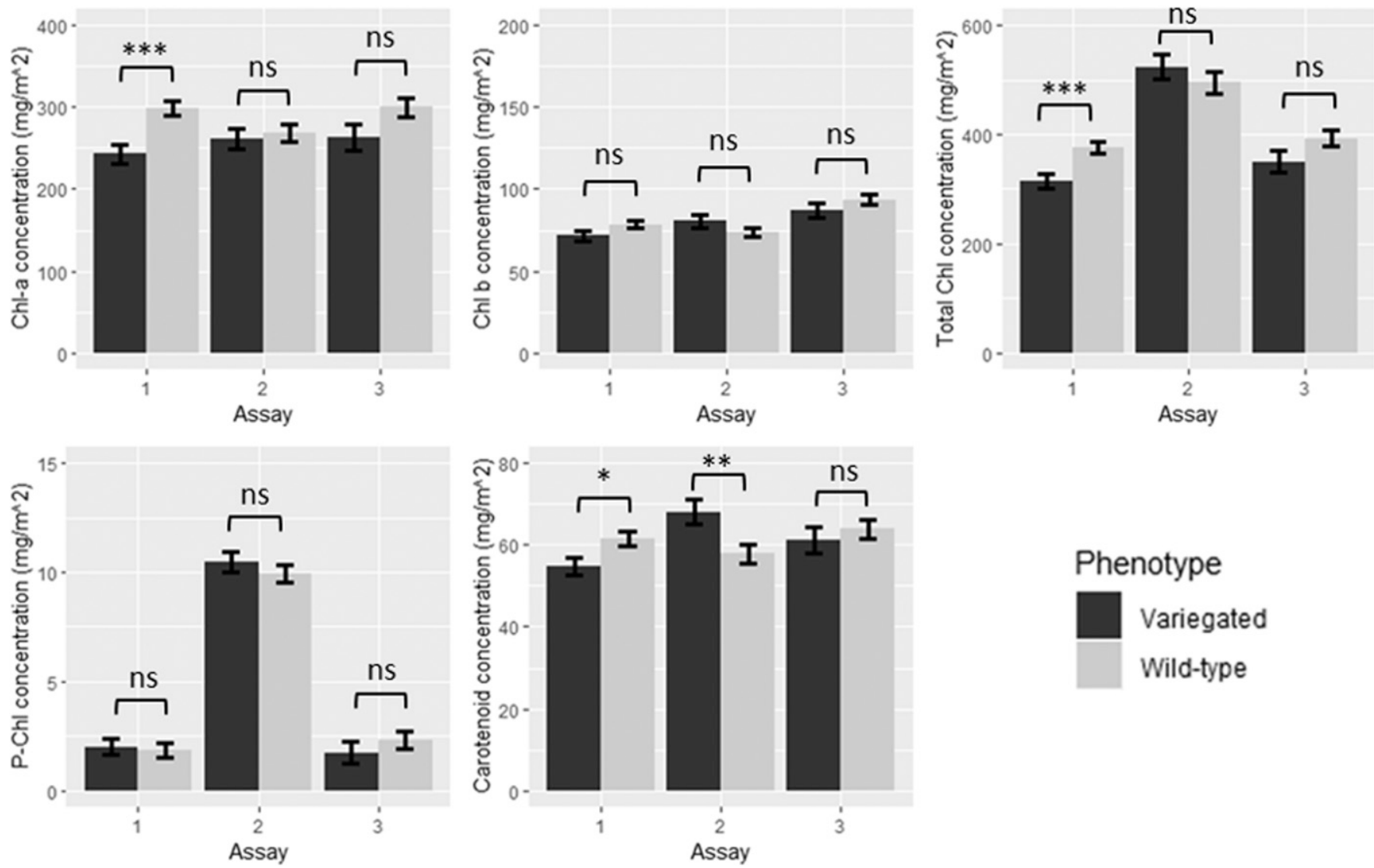

Assay

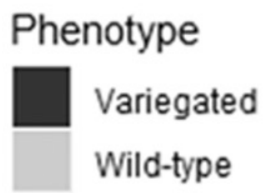

Fig. 5. Mean concentration ( $\pm \mathrm{SE})$ for leaf pigments assays (chlorophyll $a$, chlorophyll $b$, total chlorophyll, protochlorophyllide (P-Chl), and carotenoid concentration) conducted over three time points between variegated and wild-type grape seedlings. Assay 1,2 , and 3 refers to the assays performed on 22 Apr. 2020, 5 May 2020, and 22 May 2020, respectively. Significant differences between variegated and wild-type seedlings in two-sample $t$ test denoted by $* P<0.05,{ }^{* *} P<0.01,{ }^{* * *} P<0.001$; NS: nonsignificant $P$ values at $\alpha=0.05$. 

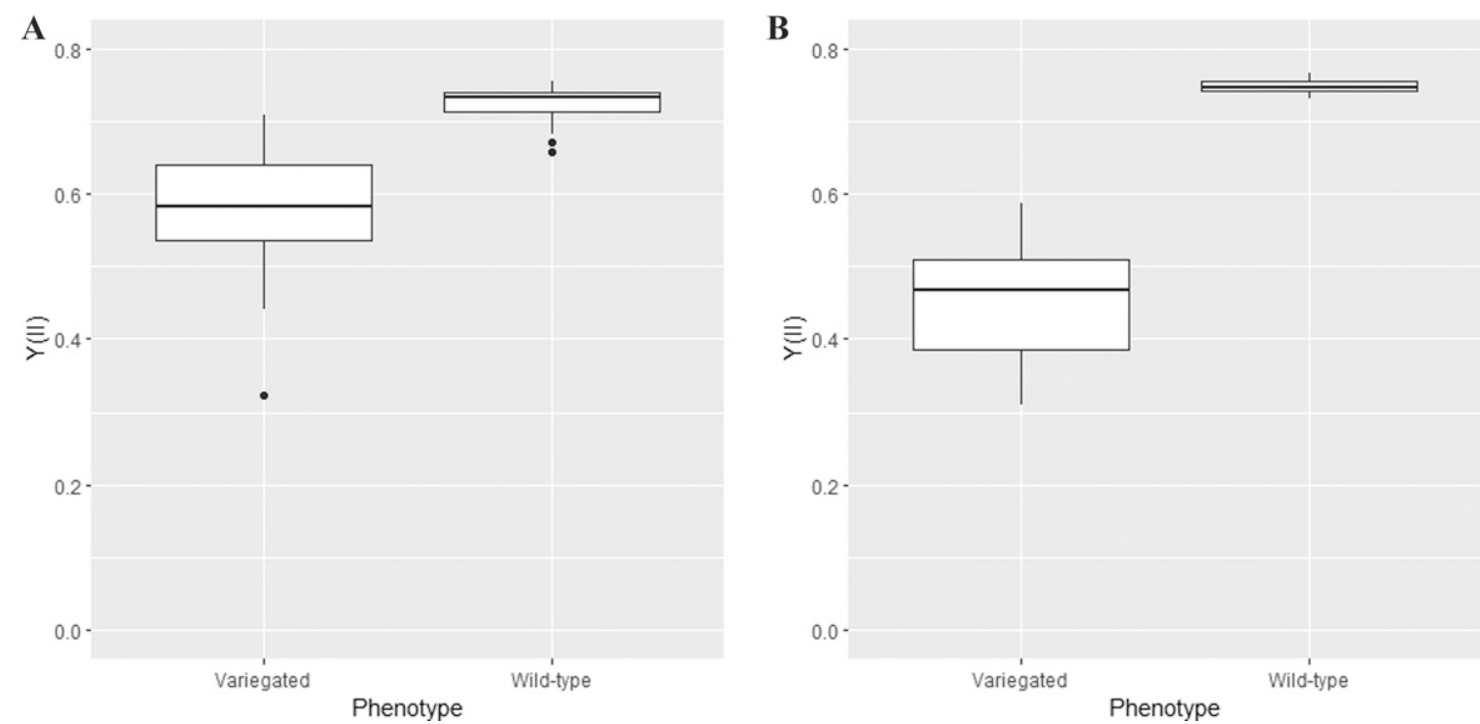

Fig. 6. Distribution of effective PSII quantum yield (Y(II)) for variegated and wild-type seedlings in the (A) 'Itasca' $\mathrm{S}_{2}$ population and (B) MN1220 $\mathrm{S}_{1}$ population. A two-sample $t$ test was performed with one rep for both populations tested.

et al., 2016; Esteban et al., 2008; Wetzel et al., 1994). The first assay showed significant differences in $\mathrm{Chl} a$, total $\mathrm{Chl}$, and carotenoid concentration $(P<0.05)$. Differences in $\mathrm{Chl} b$ were nearly significant $(P=0.058)$. The second assay 2 weeks later only showed a significant difference in carotenoid concentration, whereas the third assay found no significant differences between variegated and WT samples (Table 3; Fig. 5). These results indicate that variegation is pigment-related and significantly effects $\mathrm{Chl}$ and carotenoid production early in development but is not stably expressed as the grape plant develops new leaves. A future assay that jointly explores Chl, carotenoids, and growth rate is warranted to examine relationship of the photosystem protection to the plants overall phenotype and could be conducted over time (years) using a model perennial system like grape. It should be noted that the population sampled ('Itasca' $\mathrm{S}_{2}$ population) for this experiment only expressed the light green variegation phenotype. This likely resulted in smaller differences than would be expected between white sector variegated and WT samples in other populations and could be tested in future experiments. As mentioned previously, variegation expression is highly variable and does not always express the same among variegated populations.

Effective PSII quantum yield is significantly reduced in variegated seedlings, indicating damage to PSII. Chl fluorescence measures the photochemical efficiency of PSII and can be an indicator of stress. This technique has been used in several variegated plant species such as $A$. thaliana (Rosso et al., 2009), Arum italicum (La Rocca et al., 2011), and Begonia spp. (Sheue et al., 2012) to compare the PSII activity between variegated and WT plants. The effective PSII quantum yield, Y(II), is a parameter used to determine the quantum efficiency of PSII electron transport and is an indicator of the operating efficiency of PSII photochemistry (Murchie and Lawson, 2013). We hypothesized that variegated grape seedlings had reduced PSII activity as measured by the effective PSII quantum yield compared with WT seedlings. An 'Itasca' $S_{2}$ seedling population and an MN1220 $\mathrm{S}_{1}$ seedling population segregating for variegation revealed significant differences in effective PSII quantum yield between variegated and WT seedlings $(P<$ $0.001)$. Variegated seedlings in the 'Itasca' $S_{2}$ population had an effective PSII quantum yield that was $20 \%$ lower than WT seedlings. Similarly, variegated seedlings in the MN1220 $\mathrm{S}_{1}$ population had an effective PSII quantum yield that was $39 \%$ lower than WT seedlings (Fig. 6). Several previously mentioned studies performed measurements on variegated plants' photochemical efficiency compared with WT plants but found no significant differences between them (Esteban et al., 2008; La Rocca et al., 2011; Shelef et al., 2019; Sheue et al., 2012). This suggests that the plant is able to compensate for a reduction in photosynthetic pigments and that variegation may not have an impact on the overall photosynthesis of the plant, as hypothesized by Aluru et al. (2001) in immutans. Our findings indicate that variegation does affect photochemical efficiency in grapevine as the chloroplasts in variegated grapevine plants have damaged PSIIs, which reduces their photosynthetic capabilities and possibly suggests that the variegation may be due to chloroplast biogenesis disruption early in leaf development. Future studies could analyze other parameters such as quantum yield of regulated energy dissipation (Y(NPQ)) and quantum yield of nonregulated energy dissipation ( $\mathrm{Y}(\mathrm{NO})$ ) to lend more insight to photosystem II function in variegated grape leaves.

\section{Conclusion}

Leaf variegation in grapevine contributes to morphological differences in effected leaf tissues and results in a reduced plant growth rate. The recessive mutation observed in this study have been characterized for leaf tissue anatomy, plant development, PSII, and Chl and carotenoid production and could serve as a novel, perennial model plant for studying variegation and chloroplast biogenesis. We believe that the disruption of normal chloroplast biogenesis causes changes in mesophyll cell structure as similarly found in immutans and var2 variegated Arabidopsis mutants (Aluru et al., 2001; Chen et al., 2000). Sucrose transport from the green sectors to the white sectors may be a mechanism to maintain plant growth and development and to prevent the death of variegated tissues as reported in immutans (Aluru et al., 2006). Our findings that PSII efficacy was reduced in variegated grapevine is in contrast with previous studies in other species. Additional research on Chl and carotenoid production and the impacts of variegation on photosynthesis are warranted especially in additional light and temperature regimes. As a perennial, there is an opportunity to study this mutation in its entire ontogenetic development from germination until sexual maturation to determine what other direct and pleiotropic traits are related to chloroplast biogenesis.

\section{Literature Cited}

Aluru, M.R., F. Yu, A. Fu, and S.R. Rodermel. 2006. Arabidopsis variegation mutants: new insights into chloroplast biogenesis.. J. Expt. Bot. 579:1871-1881, doi: 10.1093/jxb/erj008.

Aluru, M.R., H. Bae, D. Wu, and S.R. Rodermel. 2001. The Arabidopsis immutans mutation affects plastid differentiation and the morphogenesis of white and green sectors in variegated plants. J. Plant Physiol. 127(1):67-77, doi: 10.1104/pp.127.1.67.

Barr, J., W.S. White, L. Chen, H. Bae, and S. Rodermel. 2004. The GHOST terminal oxidase regulates developmental programming in tomato fruit. Plant Cell Environ. 27(7):840-852, doi: 10.1111/ j.1365-3040.2004.01190.x. 
Bartley, G.E. and P.A. Scolnik. 1995. Plant carotenoids: Pigments for photoprotection, visual attraction, and human health. Plant Cell 7(7): 1027-1038, doi: 10.1105/tpc.7.7.1027.

Bondada, B. R. 2011a Anomalies in structure, growth characteristics, and nutritional composition as induced by $2,4-\mathrm{D}$ drift in phytotoxicity in grapevine (Vitis vinifera L.) leaves and clusters. J. ASHS. 136(3):165-176, doi: 10.21273/ JASHS.136.3.165.

Bondada, B.R. 2011b. Micromorpho-anatomical examination of 2, 4-D phytotoxicity in grapevine (Vitis vinifera L.) leaves. J. Plant Growth Regul. 30:185-198, doi: 10.1007/s00344-0109183-7.

Bondada, B.R., D.M. Oosterhuis, S.D. Wullschleger, K.S. Kim, and W.M. Harris. 1994. Anatomical considerations related to photosynthesis in cotton, leaves, bracts, and the capsule wall. J. Expt. Bot. 45:111-118, doi: 10.1093/ $\mathrm{jxb} / 45.1 .111$.

Borek, M., R. Baczek-Kwinta, and M. Rapacz. 2016. Photosynthetic activity of variegated leaves of Coleus $\times$ hybridus hort. cultivars characterised by chlorophyll fluorescence techniques. Photosynthetica 54(3):331-339, doi: 10.1007/s11099-016-0225-7.

Chapman, A.G. and W.H. Camp. 1932. Starch synthesis in the variegated leaves of Pelargonium. Ohio J. Sci. 32:197-217.

Chen, M., Y. Choi, D.F. Voytas, and S. Rodermel. 2000. Mutations in the Arabidopsis VAR2 locus cause leaf variegation due to the loss of a chloroplast FtsH protease. Plant J. 22(4):303-313, doi: 10.1046/j.1365-313x.2000.00738.x.

Ernst, D. and K. Schefbeck. 1988. Photooxidation of plastids inhibits transcription of nuclear encoded genes in rye (Secale cereale). J. Plant Physiol. 88(2):255-258, doi: 10.1104/pp.88.2.255.

Esteban, R., B. Fernández-Marín, J.M. Becerril, and J.I. García-Plazaola. 2008. Photoprotective implications of leaf variegation in E. dens-canis L. and P. officinalis L. J. Plant Physiol. 165(12): 1255-1263, doi: 10.1016/j.jplph.2007.07.024.

Filler, D.M., J.J. Luby, and P.D. Ascher. 1994 Incongruity in the interspecific crosses of Vitis L. Morphological abnormalities in the F2 progeny. Euphytica 78(3):227-237, doi: 10.1007/ BF00027521.
Galzy, R. and P. Galzy. 1964. Action de la temperature sur la panachure blanche de la vigne. Prog. Agr. Vitic. 162:271-280.

Graves, S., H.P. Piepho, L. Selzer, and S. Dorai-Raj. 2015. Package "multcompView". Visualizations of paired comparisons. <https://cran.r-project. org/web/packages/multcompView/multcomp View.pdf $>$.

Hara, N. 1957. Study of the variegated leaves with special reference to those caused by air spaces. J. Jpn. Bot. 16:86-101.

Kirk, J.T.O. and R.A.E. Tilney-Bassett. 1978. The Plastids: Their chemistry, structure, growth and inheritance. Elsevier/North-Holland, Amsterdam, The Netherlands.

La Rocca, N., N. Rascio, and P. Pupillo. 2011. Variegation in Arum italicum leaves. A structural-functional study. J. Plant Phys. Biochem. 49(12):1392-1398, doi: 10.1016/j.plaphy.2011. 09.009.

Moran, R. 1982. Formulae for determination of chlorophyllous pigments extracted with $\mathrm{N}, \mathrm{N}-$ dimethylformamide 1. J. Plant Physiol. 69(6):13761381, doi: 10.1104/pp.69.6.1376.

Murchie, E.H. and T. Lawson. 2013. Chlorophyll fluorescence analysis: A guide to good practice and understanding some new applications. J. Expt. Bot. 64(13):3983-3998, doi: 10.1093/jxb/ ert208.

R Core Team. 2019. R: A language and environment for statistical computing. R Foundation for Statistical Computing, Vienna, Austria $<$ https://www.R-project.org/>.

Rathjen, A.H. and S.P. Robinson. 1992. Aberran processing of polyphenol oxidase in a variegated grapevine mutant. J. Plant Physiol. 99:1619 1625, doi: 10.1104/pp.99.4.1619.

Rédei, G.P. 1963. Somatic instability caused by a cysteine-sensitive gene in Arabidopsis. Science 139: 767-769, doi: 10.1126/science.139.3556.767.

Röbbelen, G. 1968. Genbedingte RotlichtEmpfindlichkeit der Chloroplastendifferenzierung bei Arabidopsis. Planta 80(3):237-254, doi: 10.1007/BF00392394.

Rosso, D., R. Bode, W. Li, M. Krol, D. Saccon, S Wang, L.A. Schillaci, S.R. Rodermel, D.P. Maxwell, and N.P.A. Hüner. 2009. Photosynthetic redox imbalance governs leaf sectoring in the Arabidopsis thaliana variegation mutants immutans, spotty, varl, and var2. Plant Cell 21(11):3473-3492, doi: 10.1105/tpc.108.062752.

Schindelin, J., I. Arganda-Carreras, E. Frise, V. Kaynig, M. Longair, T. Pietzsch, S. Preibisch, C. Rueden, S. Saalfeld, B. Schmid, and J.Y. Tinevez. 2012. Fiji: An open-source platform for biological-image analysis. Nat. Methods 9(7):676-682, doi: 10.1038/nmeth.2019

Shelef, O., L. Summerfield, S. Lev-Yadun, S. Villamarin-Cortez, R. Sadeh, I. Herrmann, and S. Rachmilevitch. 2019. Thermal benefits from white variegation of Silybum marianum leaves. Front. Plant Sci. 10:688, doi: 10.3389/fpls.2019. 00688.

Sheue, C.R., S.H. Pao, L.F. Chien, P. Chesson, and C.I. Peng. 2012. Natural foliar variegation without costs? The case of Begonia. Ann. Bot. 109(6):1065-1074, doi: 10.1093/aob/mcs025.

Tsai, C.C., Y.J. Wu, C.R. Sheue, P.C. Liao, Y.H Chen, S.J. Li, J.W. Liu, H.T. Chang, W.L. Liu, Y.Z. Ko, and Y.C. Chiang. 2017. Molecular basis underlying leaf variegation of a Moth Orchid mutant (Phalaenopsis aphrodite subsp. formosana). Front. Plant Sci. 8:1333, doi: 10.3389/fpls.2017.01333.

Wellburn, A.R. 1994. The Spectral determination of chlorophylls a and b, as well as total carotenoids, using various solvents with spectrophotometers of different resolution. J. Plant Physiol. 144(3):307-313, doi: 10.1016/S0176-1617(11) 81192-2.

Weller, H. 2019. countcolors: Locates and counts pixels within color range(s) in images. R package version 0.9.1. <https:/CRAN.R-project. org/package $=$ countcolors $>$.

Wetzel, C.M., C.Z. Jiang, L.J. Meehan, D.F. Voytas, and S.R. Rodermel. 1994. Nuclear-organelle interactions: The immutans variegation mutant of Arabidopsis is plastid autonomous and impaired in carotenoid biosynthesis. Plant J. 6(2):161175, doi: 10.1046/j.1365-313X.1994.6020161.x.

Yu, F., A. Fu, M. Aluru, S. Park, Y. Xu, H. Liu, X. Liu, A. Foudree, M. Nambogga, and S. Rodermel. 2007. Variegation mutants and mechanisms of chloroplast biogenesis. Plant Cell Environ. 30(3):350-365, doi: 10.1111/j.13653040.2006.01630.x. 